\title{
Simulation and Modelling of near Infrared Spectroscopy (NIRS) as Brain Monitor
}

\author{
Mohamed Shaaban Ali* \\ Anesthesia, Faculty of Medicine, Assiut University, Assiut, Egypt \\ Email: msali58@hotmail.com \\ Received 11 February 2014; revised 15 March 2014; accepted 24 March 2014 \\ Copyright (C) 2014 by author and Scientific Research Publishing Inc. \\ This work is licensed under the Creative Commons Attribution International License (CC BY). \\ http://creativecommons.org/licenses/by/4.0/ \\ (c) (7) Open Access
}

Near infrared spectroscopy (NIRS) is a method for non-invasive monitoring of cerebral oxygenation and haemodynamics. Different devices provide information on changes of oxygenated $\left(\mathrm{HbO}_{2}\right)$ and deoxygenated haemoglobin $(\mathrm{HHb})$, oxidized cytochrome aa3 (CytOx) or regional oxygen saturation $\left(\mathrm{rSO}_{2}\right)$. NIRS has been used during adult and paediatric cardiac surgery.

\section{Physical Principles of NIRS}

The unique ability of light in the near-infrared (NIR) range (700 - $1300 \mathrm{~nm}$ ) to detect the oxygenation-state of living tissue was first realized by Jobsis in 1977 [1]. Since then, NIRS has emerged as a technique for in vivo and continuous monitoring of cerebral oxygenation.

This technique is based on several physical characteristics of NIR light. First, the skin, scalp and skull are relatively transparent to NIR light, allowing transmission of NIR photons into the brain. As these photons pass through the brain, they undergo attenuation as a result of scattering and absorption by specific chromophores. These chromophores are intravascular haemoglobin and intracellular cytochrome aa3. Measurement of changes in cerebral chromophore concentration is related to the overall optical attenuation of NIRS light by a modified Beer Lambert Law [2]:

$$
A=(a[c] L B)+G
$$

where $\mathrm{A}=$ the attenuation of light in optical densities, $\mathrm{a}=$ the extinction coefficient of the chromophore $\left(\mathrm{mM}^{-1} \cdot \mathrm{cm}^{-1}\right),[\mathrm{c}]=$ the concentration of chromophore $(\mathrm{mM}), \mathrm{L}=$ the distance between light entry and exit $(\mathrm{cm})$, $\mathrm{B}=\mathrm{a}$ path length factor that takes into of the increased optical path length due to scattering of light in the tissue, and $\mathrm{G}=$ a factor related to tissue and optode geometry.

The attenuation due to scattering and the geometric factor is not known and thus the concentration of chromophore cannot be quantified absolutely. Nonetheless, in a given tissue with a fixed optical geometry, it is likely to remain constant. Changes in attenuation, therefore, can be attributed solely to changes in the concentration of chromophore

$$
\Delta[\mathrm{c}]=\Delta \mathrm{A} /(\mathrm{a} \times \mathrm{L} \times \mathrm{B})
$$

where $\Delta \mathrm{C}$ is the change in chromophore concentration; $\Delta \mathrm{A}$ is the change in optical density.

*PhD, MD, Associate professor of Anesthesia. 
Optical densities are measured at several wavelengths selected for their proximity to absorption peaks of chromophores of interest. NIRS measures changes in concentration of cerebral oxyhaemoglobin $\left(\mathrm{HbO}_{2}\right)$, deoxygenated haemoglobin ( $\mathrm{HHb}$ ), and, from their sum changes of total haemoglobin (THb), as well as changes in the cerebral concentration of oxidized cytochrome aa3 (CytOx). In addition, claims are made to measure the ratio of $\mathrm{HbO}_{2} / \mathrm{THb}$ and this is reported as "regional cerebral saturation" $\left(\mathrm{rSO}_{2}\right)$ or as "tissue oxygen index" (TOI).

Cytochrome oxidase is the terminal member of the mitochondrial respiratory chain, producing the energy necessary for conversion of adenosine diphosphate (ADP) to adenosine triphosphate (ATP). If oxygen is unavailable, electron transfer cannot take place and electrons accumulate on the haem and copper atoms of cytochrome aa3, causing it to become reduced. When oxygen becomes available, electrons are transferred to oxygen and cytochrome aa3 becomes oxidised. Thus, monitoring changes in oxidised form of the enzyme cytochrome aa3 can provide valuable information on oxidation-reduction state of the enzyme and hence on oxygenation at the cellular level [3] [4].

\section{Limitations of NIRS}

NIRS has the following limitations [5]-[7]:

1) It detects regional cerebral oxygenation (small area under the optodes).

2) Optical path length is difficult to identify.

3) Arterial versus venous changes are not distinguished.

4) The effect of extracranial tissue on NIRS signal is unknown.

5) Absolute quantification is lacking.

6) Vulnerable to light and movement artifacts.

7) Dissolved oxygen not measured.

\section{NIRS Simulation and Modelling}

Several methods of simulation and modelling were used to overcome such limitations [8]-[11]. Chang et al. [9] used a simulation method for understanding photon migration dynamics in human brain based on Monte Carlo algorithm by using three-dimensional magnetic resonance imaging (MRI) data with multi-wavelength illumination. MRI imaged the human brain with five layers; scalp, skull, cerebrospinal fluid (CSF), gray matter and white matter. They found that such patient-oriented simulation model can provide significant characteristics on the optimal choice of source-detector separation within $3.3 \mathrm{~cm}$ for individualized case. Also, significant distortions were observed around cerebral cortex folding. Spatial sensitivity penetrated deeper to the brain in the case of expanded CSF. Such finding suggests that the optical method may provide not only functional signal from the brain activation but also structural information of brain atrophy with expanded CSF. It appeared that the threedimensional time-resolved brain modelling method approached the realistic human brain and provides useful information for NIRS systematic design and calibration for individualized case with prior MRI.

Others [11] described a four-layered for NIR light propagation in a human head based on Mont Carlo method. They used wave lengths of $690 \mathrm{~nm}, 800 \mathrm{~nm}$ and $1300 \mathrm{~nm}$. The four layers are scalp and skull (one layer), CSF, grey matter and white matter. They found that the wave length of $1300 \mathrm{~nm}$ is more appropriate for monitoring of human brain activity. Also, grey matter absorption was more sensitive at $1300 \mathrm{~nm}$, and the spatial resolution was improved at $1300 \mathrm{~nm}$.

It appears that NIRS is a promising brain oxygenation monitor. It has all the theoretical advantages that could make it a suitable device for real-time brain monitoring during cardiac surgery. It is to be hoped that increasingly sophisticated computer modelling will permit a better understanding of its limitations and that modern equipment will make possible the real-time correction for the scattering effects of extracerebral tissue.

\section{References}

[1] Jöbsis, F.F. (1977) Noninvasive, Infrared Monitoring of Cerebral and Myocardial Oxygen Sufficiency and Circulatory Parameters. Science, 198, 1264-1267. http://dx.doi.org/10.1126/science.929199

[2] Fallon, P., Roberts, I., Kirkham, F.J., Elliott, M.J., Lloyd-Thomas, A., Maynard, R. and Edwards, A.D. (1993) Cerebral Haemodynamics during Cardiopulmonary Bypass in Children Using Near-Infrared Spectroscopy. Annals of Thoracic Surgery, 56, 1473-1477. http://dx.doi.org/10.1016/0003-4975(93)90733-X

[3] Chan, S. and Li, P. (1990) Cytochrome c Oxidase: Understanding Nature’s Design of a Proton Pump. Biochemistry, 29, 
1-12. http://dx.doi.org/10.1021/bi00453a001

[4] Brazy, J.E. (1991) Cerebral Oxygen Monitoring with near Infrared Spectoscopy: Clinical Application to Neonates. Journal of Clincal Monitoring, 7, 325-334. http://dx.doi.org/10.1007/BF01619354

[5] Wahr, J.A., Tremper, K.K., Samra, S. and Delpy, D.T. (1996) Near-Infrared Spectroscopy: Theory and Applications. Journal of Cardiothoracic and Vascular Anesthesia, 10, 406-418. http://dx.doi.org/10.1016/S1053-0770(96)80107-8

[6] du Plessis, A.J. and Volpe, J.J. (1996) Cerebral Oxygenation and Hemodynamic Changes during Infant Cardiac Surgery: Measurements by near Infrared Spectroscopy. Journal of Biomedical Optics, 1, 373-386. http://dx.doi.org/10.1016/S1053-0770(96)80107-8

[7] Owen-Reece, H., Smith, M., Elwell, C.E. and Goldstone, J.C. (1999) Near Infrared Spectroscopy. British Journal of Anaesthesia, 82, 418-426. http://dx.doi.org/10.1093/bja/82.3.418

[8] Fukui, Y., Ajichi, Y. and Okada, E. (2003) Monte Carlo Prediction of Near-Infrared Light Propagation in Realistic Adult and Neonatal Head Models. Applied Optics, 42, 2881-2887. http://dx.doi.org/10.1364/AO.42.002881

[9] Chuang, C.C., Lee, Y.T., Chen, C.M., Hsieh, Y.S., Liu, T.C. and Sun, C.W. (2012) Patient-Oriented Simulation Based on Monte Carlo Algorithm by Using MRI Data. Biomedical Engineering Online, 17, 11-21.

[10] Boas, D., Culver, J., Stott, J. and Dunn, A. (2002) Three Dimensional Monte Carlo Code for Photon Migration through Complex Heterogeneous Media Including the Adult Human Head. Optical Express, 10, 159-170. http://dx.doi.org/10.1364/OE.10.000159

[11] Guo, Z., Cai, F. and He, S. (2013) Optimization for Brain Activity Monitoring with near Infrared Light in a FourLayered Model of the Human Head. Progress in Electromagnetics Research, 140, 277-295. http://dx.doi.org/10.2528/PIER13040203 